\title{
Evaluation of health status and its predictor among university staff in Nigeria
}

\author{
Elizabeth M. Joseph-Shehu ${ }^{1,2^{*}}$ (D) and Busisiwe P. Ncama ${ }^{1}$
}

\begin{abstract}
Background: Hypertension, diabetes mellitus and obesity share some characteristics in relation to diagnosis, management, and prevention. Overweight, obesity and waist-hip ratio (WHR) are associated with increased risk for development of diabetes and hypertension. Surveillance and regular screening exercises are essential in control and prevention of overweight, obesity, diabetes and hypertension. There is limited literature that reported on these health status parameters among university staff in low- and middle-income countries such as Nigeria. It is currently unclear whether Nigerian have a high or low proportion of metabolic risk factors. Therefore, the study aims to examine health status parameters and their predictors among university staff in Nigeria.
\end{abstract}

Methods: The study used a cross-sectional descriptive design. Data were collected from 280 university staff in Nigeria. A self-administered questionnaire with sections for sociodemographic data and physical assessment was used to gather information from the participants. Data were analysed using the Statistical Package for Social Science (IBM-SPSS version 25). Univariable and multivariable logistic regression was conducted to explore the association between predictors and health status parameters of the participants.

Result: The response rate was $87.5 \%$. University staff had mean systolic blood pressure of $132.04 \mathrm{mmHg} \pm 19$. $20 \mathrm{mmHg}$, diastolic blood pressure of $78.11 \mathrm{mmHg} \pm 10.81 \mathrm{mmHg}$, body mass index of $27.74 \pm 5.22$, waist-hip ratio of $0.88 \pm 0.68$ and random blood sugar of $98.65 \pm 21.30 \mathrm{mg} / \mathrm{dL}$. Predictors of high blood pressure were age (adjusted odds ratio $[\mathrm{aOR}]=1.10, \mathrm{Cl} 95 \%$ : [1.05-1.14]) and gender (aOR=0.5, Cl 95\%: [0.8-0.9]) and predictors of body mass index were gender ( $\mathrm{aOR}=2.3, \mathrm{Cl} 95 \%$ : [1.3-4.2]) and religion $(\mathrm{aOR}=0.3, \mathrm{Cl} 95 \%$ : [0.2-0.7]). Gender and age had statistically significant association with waist-hip ratio and random blood sugar respectively.

Conclusion: The prevalence rates of high blood pressure and random blood sugar; overweight, obesity and risk WHR are on the increase compared to previous studies. Lifestyle modification, organized and explicit health campaigns coupled with regular screening and surveillance will contribute to the prevention and control of noncommunicable diseases.

Keywords: Health status, Noncommunicable diseases, Blood pressure, Waist-hip ratio, Body mass index, Random blood sugar, University staff, Nigeria

\section{Background}

Health status is defined in relation to blood pressure, body mass index (BMI), waist-hip ratio (WHR) and random blood sugar (RBS). These health status parameters were used to assessed cardiometabolic disorders which include disorders in glucose regulation, central obesity,

\footnotetext{
* Correspondence: ejoseph-shehu@noun.edu.ng; lizjoe26@gmail.com 'School of Nursing and Public Health, Postgraduate Office, Ground Floor, George Campbell Building, Howard College Campus, University of KwaZulu-Natal, Durban, South Africa

${ }^{2}$ Department of Nursing Science, Faculty of Health Sciences, National Open University of Nigeria, Abuja, Nigeria
}

dyslipidaemia and hypertension [1]. These cardiometabolic disorders are risk factors for the development of noncommunicable diseases (NCDs) such as cardiovascular diseases and diabetes.

The burden of noncommunicable diseases is well documented in low- and middle-income countries (LMICs) [2-4]. Eighty per cent of premature deaths associated with NCDs occur in LMICs, and they usually affect ages between 30 and 69 years [5-7]. Statistics show that there is an increase in global deaths associated with NCDs annually. In 2005, 60.3\% deaths annually were attributed to 
NCDs [8], and currently the figure has risen to $70 \%$ [5, 7]. NCDs are no longer diseases of the affluent, as LMICs have the highest mortality and morbidity associated with the disease [9]. The impact of NCDs is not confined to quality of life of the affected individual alone; NCDs also affect the families and the national economy [9].

Cardiovascular diseases (CVDs) alone have a global annual death rate of 17.7 million (44.3\%) and the figure for diabetes mellitus is about 4.0\% [5]. Hypertension, diabetes mellitus and obesity share some characteristics in relation to diagnosis, management, and prevention $[10,11]$. Waist-hip ratio (WHR) is an indicator that complements BMI measurement to identify individuals at risk of obesity-related morbidity [12]. Overweight, obesity and WHR [12] are associated with increased risk for development of diabetes, hypertension [13-15] and ischemic heart diseases [16]. BMI is significantly associated with manifestation of angina, myocardial infarction, heart failure and sudden death in both males and females [17]. Hypertension, diabetes and hyperlipidaemia are linked with coronary heart disease that have high mortality and morbidity globally [18]. Hence they are of public health concern globally [19]. One in three adults globally have raised blood pressure which is the cause of about $50 \%$ of all deaths from stroke and other heart diseases; one in 10 adults have diabetes mellitus [19] and one in four women are overweight [20].

The prevalence rate of diabetes in Africa varies between 1 to $3 \%$ and $5 \%$ to $6 \%$ among rural and urban dwellers respectively [21]. According to the International Diabetic Federation, Nigeria has the highest number of people living with diabetes and impaired fasting glucose in Africa [19]. Literature showed that by 2030, development of diabetes in developing countries will be between 45 and 64 years $[11,20,22]$. Obesity increases the prevalence rate of type 2 diabetes [20, 21], and its prevention is critical to reducing the onset of type 2 diabetes [19]. Most deaths related to CVDs occur in the working age range of 35 to 64 years [11] when the individual is still very productive. Hypertension and diabetes are usually co-existed [19].

Overweight and obesity are on the increase in LMICs [23] and will soon surpass their prevalence in the developed countries [4]. Among university staff in Nigeria there is a continued increase in the prevalence of obesity, which may be attributed to the nature of their work [24]. Development of abdominal fat occurs among both academic and non-academic staff, indicating growth of central abdominal fat [24] that increases the risk for metabolic and cardiovascular disorders [25]. World Health Organization (WHO) reports have documented that a 12-year follow-up of middle-aged men with high WHR was associated with increased risk of myocardial infarction, stroke, premature deaths and insulin resistance [12].

High blood pressure is a risk factor for stroke, ischaemic heart diseases, heart failure and chronic kidney diseases [26]. Commonly referred to as the silent killer [27], it is liable to remain untreated [28] since most people are not aware of the symptoms or warning signs. Untreated hypertension may lead to coronary heart diseases or congestive heart failure, which account for $50 \%$ of all deaths associated with hypertension; $33 \%$ of untreated hypertension may lead to stroke, and $10-15 \%$ will result in renal failures [26]. Prevalence rates for hypertension in Nigeria, as reported in various studies $[6,7,19,26]$, differ from one zone to another.

Overweight and obesity increase the rates of premature mortality and morbidity from CVDs and worsen the prognosis of type 2 diabetes, chronic back pain and osteoarthritis [23]. CVDs and diabetes mellitus account for $30 \%$ of global mortality, and $80 \%$ of these deaths were recorded in LMICs [29]. Expedient intervention is called for, especially among university staff [24], in response to increase in the burden of CVDs [3] and steady increase in prevalence rates for hypertension $[26,28]$ and diabetes [19] in Nigeria - coupled with the link for the latter two with overweight and obesity [20, 23, 30].

There is a paucity of data on health status that considers the four parameters that are important in the development of CVDs among university staff in Nigeria. Furthermore, there is limited literature that reported on blood pressure, BMI, WHR RBS among university staff $[31,32]$ in LMICs such as Nigeria. It is unclear whether Nigerian have a high or low proportion of metabolic risk factors. Hence, it is essential to examine the health status of this population before developing an intervention to prevent and control NCDs among them. The aim of this study is to examine the health status and its predictors among university staff in Nigeria.

\section{Methods}

This study is a cross-sectional, descriptive study design that was conducted among university staff in Nigeria between October and December 2016. The selected university is the largest in term of spread, and student population. The university has a headquarters and over 70 satellite campuses with 2657 staff across the country as of 2016. The study settings were spread across the six geopolitical zones in Nigeria; Fig. 1 shows the study locations. One state was randomly selected (ballot method) in each geographical zone and purposive selection was used in choosing the institution headquarters and the study centres.

$G^{*}$ Power 3 [33] was used in determine a figure of 231 for the study sample size. The sample size was increased by $15 \%$ to make it 266 to allow for a non-parametric 


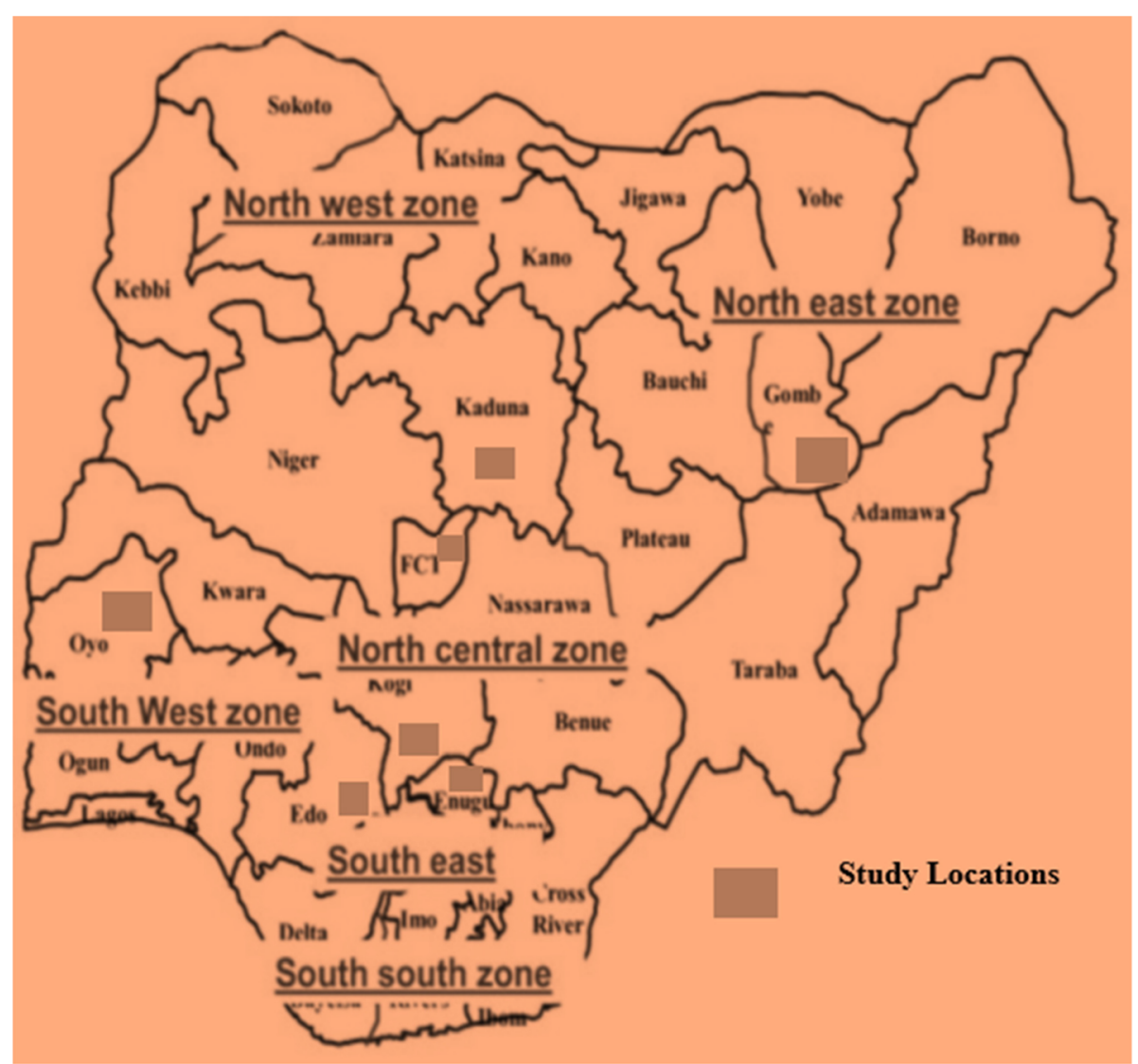

Fig. 1 Map of Nigeria showing the six-geopolitical zones and study locations retrieved from Wordofmonk.wordpress.com on February 2016

equivalent should the proposed parametric test not be valid. The study participants were drawn from the major study centers (usually one per state) in each of the selected states. A convenience sampling technique was used to select participants for the study. Data were collected from 141 participants in the selected study centers and 139 from headquarters who were willing to be part of the study.

A self-administered questionnaire (Additional file 1) that consisted of two sections was used to gather data for the study. The first section gathered information on sociodemographic variables: age, gender, study locations, educational qualification, religion, designation, average monthly income and marital status. The second section consisted of health assessment measures for blood pressure, random blood sugar, height, weight, waist and hip circumference.

Ethical approval for the study was obtained from Ethics Committee of the University of KwaZulu-Natal, Durban, South Africa (BFC423/16) and the National Open University of Nigeria Health Research Ethics Review Committee (NHREC 04). An information sheet containing details of the survey was given to each participant. They were informed and assured that anonymity and confidentiality would be maintained. They were further assured that participation in this study was entirely voluntary, that they could withdraw from the study at any time, and that data from the survey would be used for scientific research purposes only.

Age was recorded in years; average monthly income less than N100 000 was recorded as low income, N101 000N200,000 as middle income and above N200 000 as high income. The sociodemographic variables under study were age, gender, religion, location of staff, average monthly income, marital status, designation and highest educational level.

The health assessments section measured the cardiometabolic status (blood pressure, random blood sugar, height, weight, waist and hip circumference). Participants were made to rest in a sitting position for between 5 and 10 min before taking the blood pressure test. A digital sphygmomanometer was used to measure blood pressure twice, with an interval of $10 \mathrm{~min}$, and an average of the two was recorded as the participant's blood pressure. The blood pressure readings of the participants were described as normal systolic blood pressure when systolic measured below $120 \mathrm{mmHg}$, systolic prehypertension was between $120 \mathrm{mmHg}$ and $139 \mathrm{mmHg}$, and systolic hypertension was $<140 \mathrm{mmHg}$ and above. 
Normal diastolic blood pressure was diastolic measuring < $80 \mathrm{mmHg}$, diastolic prehypertension was blood pressure measuring between $80 \mathrm{mmHg}$ and $89 \mathrm{mmHg}$, and diastolic hypertension was blood pressure measuring 90 and above $[27,34]$. RBS was measured using glucometer and results were in $\mathrm{mg} / \mathrm{dL}$. RBS level of < 70-139 (3.9-7.7 $\mathrm{mmol} / \mathrm{l})$ and $>140(7.8 \mathrm{mmol} / \mathrm{l})$ and above were classified as normal and high RBS respectively. Height was measured in centimetres accurate to $0.1 \mathrm{~cm}$ using stadiometer. Weight was accurate to $0.1 \mathrm{~kg}$ using weighing scale. BMI was calculated by dividing body weight in $\mathrm{kg}$ by the square of the individual's height in metres. BMI was classified according to the Centre for Disease Control [35] as $\leq 18=$ underweight, 18.5-24.9= normal or healthy weight, 25.0-29.9= overweight and $\geq 30=$ obesity. Waist circumference was measured at the midpoint between the lower margin of the least palpable rib and the top of the iliac crest and hip circumference was measured around the widest portion of the buttock, both with a tape measure accurate to $0.1 \mathrm{~cm}$. WHR was calculated by dividing waist circumference by hip circumference. WHR classification based on WHO is healthy when $\leq 0.85$ for women and $\leq$ 0.90 for men. Hence, we categorized WHR as healthy WHR when calculated at $\leq .85$ and as risk WHR for $>0.86$ [12].

\section{Data analysis}

Data were analysed using Statistical Package for Social Science (IBM-SPSS version 25). Continuous variables were summarized as the mean \pm standard deviation. Categorical data were summarized using frequency, percentage and cross-tabulation. Univariable and multivariable logistic regression was conducted to explore the association between sociodemographic variables and health status parameters of the participants. We initially performed a univariable logistic regression to estimate the association between each of the cardiometabolic-status and sociodemographic characteristics of the participants. Only the sociodemographic variables that were significant were put in the final models for each health status parameter. Hence, all the health status parameters were regrouped into binary (normal and high) as they were treated as the dependent variables. The blood pressure readings of the participants were therefore further classified as normal blood pressure when systolic measured $<140$ and diastolic < 90, and as high blood pressure when systolic blood pressure $\geq 140$ and diastolic $\geq 90$. BMI was classified as normal BMI when calculated as $<18-24.9$ and high BMI when the calculation was $>25.0$. Four models were developed for each health status parameter and sociodemographic variable. Odds ratio (OR) was estimated with 95\% confidence interval (CI). Cases with missing value/s were defined as no response, treated and expressed in frequency and percentage. However, in the regression analysis, missing cases were excluded and treated as missing. Statistical significance was determined at a $p$-value $\leq 0.05$.

\section{Results}

Table 1 shows the sociodemographic variables of the study participants. The largest age group among participants $(45.5 \%)$ was the $30-39$ years age group and mean age of participants was $40.13 \pm 9.53$ years, $55.7 \%$ were male, $87.1 \%$ were Christians, more than half $(58.6 \%)$ had university education, $51.4 \%$ were senior non-academic staff, $79.3 \%$ were married, and $49.3 \%$. were in the low monthly income category (less than N100 000).

Figure 2 gives a summary of participants' health status. Mean systolic blood pressure was $132.04 \pm 19.20$ with minimum value of $90 \mathrm{mmHg}$ and maximum value of $195 \mathrm{mmHg}$. Mean diastolic blood pressure was 78.11 \pm

Table 1 Sociodemographic variables of Nigerian university staff

\begin{tabular}{|c|c|c|}
\hline Age & Frequency & Percentage \\
\hline $20-29$ & 30 & 10.7 \\
\hline $30-39$ & 126 & 45.0 \\
\hline $40-49$ & 67 & 23.9 \\
\hline $50-59$ & 46 & 16.4 \\
\hline $60-69$ & 11 & 3.9 \\
\hline \multicolumn{3}{|l|}{ Gender } \\
\hline Male & 156 & 55.7 \\
\hline Female & 124 & 44.3 \\
\hline \multicolumn{3}{|l|}{ Location of the study } \\
\hline Headquarter & 139 & 49.6 \\
\hline Study centres & 141 & 50.4 \\
\hline \multicolumn{3}{|l|}{ Religion } \\
\hline Christian & 244 & 87.1 \\
\hline Islam & 36 & 12.9 \\
\hline \multicolumn{3}{|l|}{ Marital status } \\
\hline Married & 207 & 73.9 \\
\hline Single & 73 & 26.1 \\
\hline \multicolumn{3}{|l|}{ Educational qualification } \\
\hline Primary school & 16 & 5.7 \\
\hline Secondary school & 56 & 20.0 \\
\hline College certificate & 44 & 15.7 \\
\hline University certificate & 164 & 58.6 \\
\hline \multicolumn{3}{|l|}{ Designation } \\
\hline Academic Staff & 30 & 10.7 \\
\hline Senior Non-academic Staff & 144 & 51.4 \\
\hline Junior Non-academic Staff & 106 & 35.4 \\
\hline No Response & 7 & 2.5 \\
\hline \multicolumn{3}{|l|}{ Average monthly income } \\
\hline Low income & 138 & 49.3 \\
\hline Middle income & 115 & 41.1 \\
\hline High income & 27 & 9.6 \\
\hline
\end{tabular}




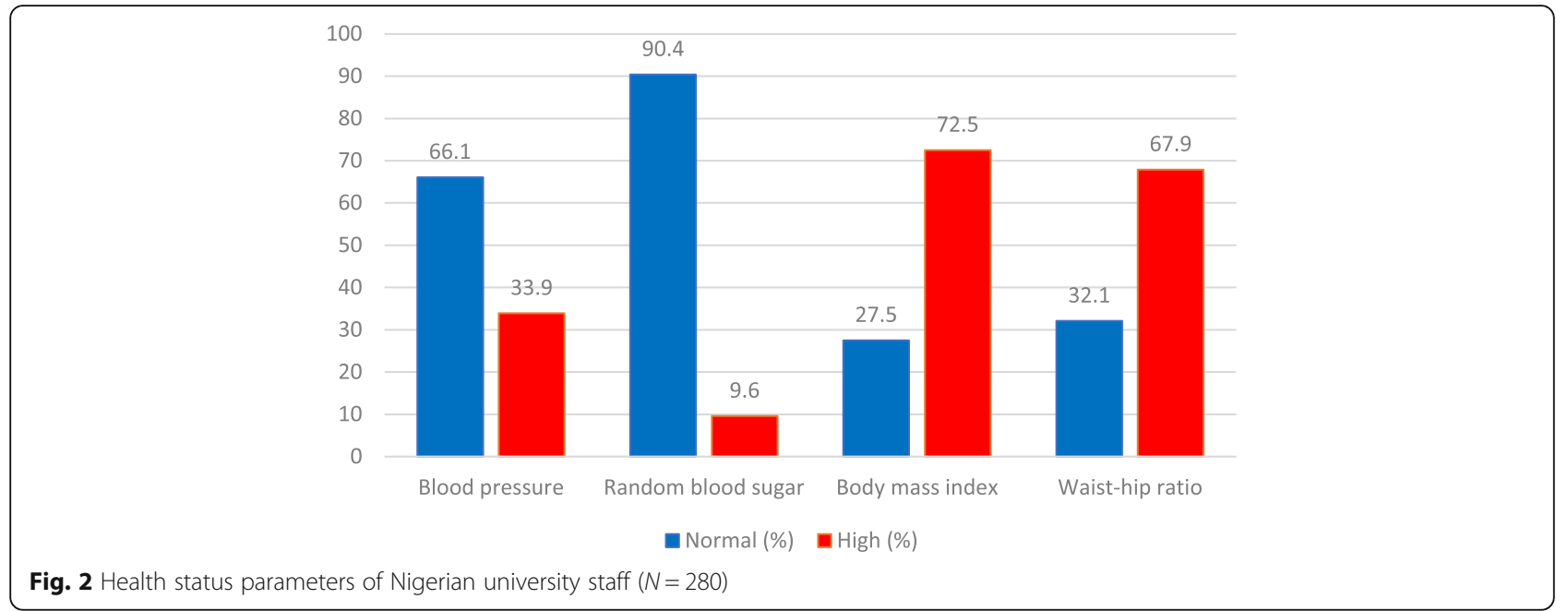

0.81 with minimum value of $48 \mathrm{mmHg}$ and maximum value of $116 \mathrm{mmHg}$. Mean BMI was $27.74 \pm 5.22$ and ranged between 16 and 52 . Mean WHR was $0.88 \pm 0.63$ ranges between $0.72-1.24$. Mean RBS was $98.65 \pm 21.30$ and ranged between 69 and $222 \mathrm{mg} / \mathrm{dl}$. Prevalence of high blood pressure was $33.9 \%$. Prevalence of high BMI was $72.5 \%$ and high WHR was $67.9 \%$. Prevalence of high RBS was 9.6\%.
To determine the predictor(s) of participants' health status we conducted univariable logistic regression to analyse the relationship between health status parameters (body mass index, blood pressure, random blood sugar and waist-hip ratio) and predictors (age, gender, religion, highest educational level, designation and average monthly income), with crude odds ratios and 95\% confidence intervals being estimated for each predictor. We further

Table 2 Univariable and multivariable odds ratios $(95 \% \mathrm{Cl})$ for predictors of high blood pressure among university staff

\begin{tabular}{|c|c|c|c|c|c|c|c|}
\hline \multirow[t]{2}{*}{ Explanatory variables } & \multirow{2}{*}{$\begin{array}{l}\text { Categories of } \\
\text { explanatory variables }\end{array}$} & \multicolumn{3}{|l|}{ Univariable } & \multicolumn{3}{|l|}{ Multivariable } \\
\hline & & Crude Odds ratio & Confidence interval & $p$-value & Adjusted odds ratio & Confidence interval & $p$-value \\
\hline Age & & 1.096 & $1.064-1.129$ & 0.000 & 1.098 & $1.054-1.144$ & 0.000 \\
\hline \multirow[t]{2}{*}{ Gender } & Male & 1 & & & 1 & & \\
\hline & Female & 0.629 & $0.379-1.045$ & 0.073 & 0.501 & $0.275-0.912$ & 0.024 \\
\hline \multirow[t]{2}{*}{ Working locations } & Headquarter & 1 & & & 1 & & \\
\hline & Study centres & 2.355 & $1.413-3.921$ & 0.001 & 1.707 & $0.936-3.113$ & 0.081 \\
\hline \multirow[t]{2}{*}{ Religion } & Christian & 1 & & & & & \\
\hline & Islam & 0.838 & $0.393-1.786$ & 0.647 & & & \\
\hline \multirow[t]{2}{*}{ Marital status } & Single & 1 & & & 1 & 1 & \\
\hline & Married & 3.028 & $1.563-5.865$ & 0.001 & 1.386 & $0.652-2.946$ & 0.396 \\
\hline \multirow[t]{4}{*}{ Highest education level } & Primary & 1 & & & 1 & & \\
\hline & Secondary & 0.161 & $0.041-0.629$ & 0.009 & 0.562 & $0.121-2.600$ & 0.461 \\
\hline & Colleges & 0.119 & $0.029-0.485$ & 0.003 & 0.612 & $0.122-3.078$ & 0.551 \\
\hline & University & 0.085 & $0.023-0.311$ & 0.000 & 0.483 & $0.095-2.454$ & 0.381 \\
\hline \multirow[t]{4}{*}{ Designation } & No response & 3.474 & $0.369-32.743$ & 0.277 & & & \\
\hline & Academic & 1.927 & $0.224-16.556$ & 0.550 & & & \\
\hline & Senior non-academic & 5.647 & $0.656-48.643$ & 0.115 & & & \\
\hline & Junior non-academic & 1 & & & & & \\
\hline \multirow[t]{3}{*}{ Average monthly income } & Low & 1 & & & 1 & & \\
\hline & Medium & 0.407 & $0.233-0.711$ & 0.002 & 0.497 & $0.217-1.136$ & 0.098 \\
\hline & High & 1.577 & $0.689-3.609$ & 0.281 & 0.596 & $0.170-2.091$ & 0.419 \\
\hline
\end{tabular}


conducted multivariable logistic regression for all the predictors that were significantly associated with each health status in the univariable analysis. Four models were developed for each of the health status parameters.

The univariable logistic regression (Table 2) shows that age, gender, working location, marital status, highest educational level and average monthly income each had a statistical significant association with blood pressure of the participants. All the factors that had statistically significant association with blood pressure in the univariable analysis were used to build the multivariable logistic regression model. The final model reveals that age $(\mathrm{aOR}=1.10$; $\mathrm{CI}$ 95\%: [1.05-1.14]) and gender ( $\mathrm{aOR}=0.5 ; \mathrm{CI} 95 \%$ : $[0.3-0.9])$ were predictors of high blood pressure. Furthermore, employees in the institution study centres and married were more likely to develop high blood pressure, while highly educated employees with medium and high monthly income were less likely to have high blood pressure.

Age, gender, religion, marital status, designation and monthly income had statistically significant association with high BMI. The multivariable logistic regression results (Table 3) further demonstrated that gender $(\mathrm{aOR}=$ 2.3, CI 95\%: [1.2-4.2]) and religion $(\mathrm{aOR}=0.3$, CI 95\%: [0.2-0.7]) were the factors that statistically significantly associate with high BMI. Older $(\mathrm{aOR}=1.0, \mathrm{CI} 95 \%$ : [0.1-1.8]) and married participants $(\mathrm{aOR}=1.90$, CI $95 \%$ :
[0.96-3.78]) were more likely to have high BMI but not statistically significant. Muslim participants were less likely to have high BMI $(\mathrm{aOR}=0.3$, CI 95\%: [0.15-0.72]) and is statistically significant to high BMI.

Table 4 give a summary of the predictors of high waist-hip ratio. Gender (OR=0.3, CI 95\%: [0.2-0.4]) is the only factor that had statistical significant association with high waist-hip ratio among the participants.

Table 5, giving the final model of health status shows that only age $(\mathrm{OR}=1.04, \mathrm{CI} 95 \%$ : [1.00-1.09]) had a statistically significant relationship with RBS.

\section{Discussion}

Our study assessed the health status of the university staff in Nigeria and its predictors. The study showed that quite a number of our study participants had elevated health status parameters. Age and gender were predictors of high blood pressure and gender and religion were predictors of BMI. Furthermore, worker's location, marital status, monthly income, designation, highest education, religion, gender and age had statistically significant relationship with one or more measures of the health status As mentioned in the background of the study, overweight and obesity are linked to the development of CVDs, diabetes [2] and cancer [15].

Table 3 Univariable and multivariable odds ratios (95\% Cl) for predictors of high body mass index among university staff

\begin{tabular}{|c|c|c|c|c|c|c|c|}
\hline \multirow[t]{2}{*}{ Explanatory variables } & \multirow{2}{*}{$\begin{array}{l}\text { Categories of } \\
\text { explanatory variables }\end{array}$} & \multicolumn{3}{|l|}{ Univariable } & \multicolumn{3}{|l|}{ Multivariable } \\
\hline & & Crude odds ratio & Confidence interval & $p$-value & Adjusted odds ratio & Confidence interval & $p$-value \\
\hline Age & & 1.054 & $1.021-1.087$ & 0.001 & 1.037 & $0.997-1.079$ & 0.071 \\
\hline \multirow[t]{2}{*}{ Gender } & Male & 1 & & & 1 & & \\
\hline & Female & 2.525 & $1.434-4.446$ & 0.001 & 2.281 & $1.252-4.156$ & 0.007 \\
\hline \multirow[t]{2}{*}{ Working locations } & Headquarter & 1 & & & & & \\
\hline & Study centre & 0.738 & $0.436-1.250$ & 0.259 & & & \\
\hline \multirow[t]{2}{*}{ Religion } & Christian & 1 & & & 1 & & \\
\hline & Islam & 0.364 & $0.178-0.746$ & 0.006 & 0.330 & $0.151-0.722$ & 0.006 \\
\hline \multirow[t]{2}{*}{ Marital status } & Single & 1 & & & 1 & & \\
\hline & Married & 0.458 & $0.259-0.809$ & 0.007 & 1.903 & $0.957-3.784$ & 0.067 \\
\hline \multirow[t]{4}{*}{ Highest education level } & Primary & 1 & & & & & \\
\hline & Secondary & 1.202 & $0.391-3.698$ & 0.748 & & & \\
\hline & Colleges & 2.644 & $0.786-8.900$ & 0.116 & & & \\
\hline & University & 2.579 & $0.900-7.386$ & 0.078 & & & \\
\hline \multirow[t]{4}{*}{ Designation } & No response & 3.429 & $0.397-29.618$ & 0.263 & 5.115 & $0.504-51.940$ & 0.168 \\
\hline & Academic & 3.714 & $1.200-11.493$ & 0.023 & 3.198 & $0.710-14.405$ & 0.130 \\
\hline & Senior non-academic & 1.714 & $0.982-2.991$ & 0.058 & 1.8431 & $0.765-4.493$ & 0.173 \\
\hline & Junior non-academic & 1 & & & 1 & & \\
\hline \multirow[t]{3}{*}{ Average monthly income } & Low & 1 & & & 1 & & \\
\hline & Medium & 1.605 & $0.924-2.789$ & 0.093 & 0.934 & $0.391-2.229$ & 0.878 \\
\hline & High & 6.456 & $1.466-28.437$ & 0.014 & 1.522 & $0.245-9.437$ & 0.652 \\
\hline
\end{tabular}


Table 4 Univariable and multivariable odds ratios (95\% Cl) for predictors of high waist-hip ratio among university staff

\begin{tabular}{|c|c|c|c|c|c|c|c|}
\hline \multirow[t]{2}{*}{ Explanatory variables } & \multirow{2}{*}{$\begin{array}{l}\text { Categories of } \\
\text { explanatory variables }\end{array}$} & \multicolumn{3}{|l|}{ Univariable } & \multicolumn{3}{|l|}{ Multivariable } \\
\hline & & Crude odds ratio & Confidence interval & $p$-value & Adjusted odds ratio & Confidence interval & $p$-value \\
\hline Age & & 1.027 & $0.999-1.056$ & 0.056 & & & \\
\hline \multirow[t]{2}{*}{ Gender } & Male & 1 & & & & & \\
\hline & Female & 0.273 & $0.161-0.463$ & 0.000 & & & \\
\hline \multirow[t]{2}{*}{ Working locations } & Headquarter & 1 & & & & & \\
\hline & Study centre & 0.957 & $0.579-1.580$ & 0.862 & & & \\
\hline \multirow[t]{2}{*}{ Religion } & Christian & 1 & & & & & \\
\hline & Islam & 1.268 & $0.583-2.758$ & 0.549 & & & \\
\hline \multirow[t]{2}{*}{ Marital status } & Single & 1 & & & & & \\
\hline & Married & 0585 & $0.336-1.019$ & 0.058 & & & \\
\hline \multirow[t]{4}{*}{ Highest education level } & Primary & 1 & & & & & \\
\hline & Secondary & 0.449 & $0.114-1.772$ & 0.253 & & & \\
\hline & Colleges & 0.692 & $0.166-2.890$ & 0.614 & & & \\
\hline & University & 0.433 & $0.119-1.583$ & 0.208 & & & \\
\hline \multirow[t]{4}{*}{ Designation } & No response & 1 & & & & & \\
\hline & Academic & 3.281 & $0.380-28.359$ & 0.280 & & & \\
\hline & Senior non-academic & 0.820 & $0.355-1.898$ & 0.643 & & & \\
\hline & Junior non-academic & 1.328 & $0.769-2.294$ & 0.309 & & & \\
\hline \multirow[t]{3}{*}{ Average monthly income } & Low & 1 & & & & & \\
\hline & Medium & 0.948 & $0.559-1.609$ & 0.844 & & & \\
\hline & High & 1.112 & $0.452-2.735$ & 0.818 & & & \\
\hline
\end{tabular}

The findings of our study are similar to another study conducted among university staff in south-west Nigeria where $75 \%$ of the study population had two or more cardiovascular risk factors [31]. Also, a study conducted among the market population in Enugu, Southeast Nigeria reported similar findings in relation to blood pressure, WHR and BMI [28]. There were high prevalence rate of hypertension (33\%) and high BMI (72.5\%) in this current study compared to the study conducted among a semi-urban community in South South Nigeria, that reported prevalence rates of hypertension and high BMI to be to be $15 \%$ and $51.2 \%$ respectively [36]. The prevalence rates of both systolic and diastolic hypertension reported is higher than that reported among rural dwellers in South West Nigeria [37]. Despite the differences in the prevalence rate of hypertension in term of geographical location, evidence from two reviews conducted on the prevalence of hypertension showed that there is a steady increase in the prevalence of hypertension in both rural and urban areas [3, 26]. There is wide variation between the prevalence rates of overweight and obesity found in this current study compared to review reports on BMI between 2001 and 2012 which were between 28.4 and $57.3 \%$ [38].

This study findings reveal that religion had statistical significant impact on BMI and Muslim participants were less likely to have high BMI. Similar results were obtained among England and Australia population where religious denomination [39] and religion affiliation [40] had statistical significant relationship with high BMI. Lycett (2015), further reported that Christian participants had higher BMI values compared to participants with other religion faith [40]. The explanation to this current study results might be that periodic fasting of Islamic religion could have contributed to the lower BMI values. According to Levitt, type 2 diabetes accounted for $90.0 \%$ of all cases of diabetes in sub-Sahara Africa [41]. Another study reported $2.5 \%$ prevalence rate of impaired fasting blood sugar among the semi-urban population in Northern Nigeria [42]. Our study reported that 9.5\% of the population had an abnormal RBS value.

The high prevalence of overweight (41.4\%), obesity (31.8\%) and risk WHR (67.9\%) is worrisome because of their relationship with CVDs and diabetes [1, 7, 28, 41, 43]. A recent document released by the American Heart Association [44] defines elevated blood pressure as systolic of 120 and above and diastolic of 80 and above [45]. This definition will increase the number of our study participants with elevated blood pressure to $48.2 \%$. Our study reported that females are less likely to have high blood pressure compared to their male counterpart. The possible explanation to this findings is that 
Table 5 Univariable and multivariable odds ratios $(95 \% \mathrm{Cl})$ for predictors of high random blood sugar among university staff

\begin{tabular}{|c|c|c|c|c|c|c|c|}
\hline \multirow[t]{2}{*}{ Explanatory variables } & \multirow{2}{*}{$\begin{array}{l}\text { Categories of } \\
\text { explanatory variables }\end{array}$} & \multicolumn{3}{|l|}{ Univariable } & \multicolumn{3}{|l|}{ Multivariable } \\
\hline & & Crude odds ratio & Confidence interval & $p$-value & Adjusted odds ratio & Confidence interval & $p$-value \\
\hline Age & & 1.044 & $1.003-1.086$ & 0.037 & & & \\
\hline \multirow[t]{2}{*}{ Gender } & Male & 1 & & & & & \\
\hline & Female & 1.087 & $0.484-2.443$ & 0.840 & & & \\
\hline \multirow[t]{2}{*}{ Working locations } & Headquarter & 1 & & & & & \\
\hline & Study centre & 1.385 & $0.613-3.133$ & 0.434 & & & \\
\hline \multirow[t]{2}{*}{ Religion } & Christian & 1 & & & & & \\
\hline & Muslim & 1.261 & $0.408-3.897$ & 0.687 & & & \\
\hline \multirow[t]{2}{*}{ Marital status } & Single & 1 & & & & & \\
\hline & Married & 2.051 & $0.682-6.167$ & 0.201 & & & \\
\hline \multirow[t]{4}{*}{ Highest education level } & Primary & 1 & & & & & \\
\hline & Secondary & 0.231 & $0.050-1.057$ & 0.059 & & & \\
\hline & Colleges & 0.220 & $0.043-1.120$ & 0.068 & & & \\
\hline & University & 0.302 & $0.087-1.054$ & 0.060 & & & \\
\hline \multirow[t]{4}{*}{ Designation } & No response & 1.667 & $0.180-$ & 0.653 & & & \\
\hline & Academic & 0.714 & 15.425 & 0.678 & & & \\
\hline & Senior non- academic & 1.077 & $0.146-3.502$ & 0.869 & & & \\
\hline & Junior non-academic & 1 & $0.447-2.595$ & & & & \\
\hline \multirow[t]{3}{*}{ Average monthly income } & Low & 1 & & & & & \\
\hline & Medium & 1.221 & $0.509-2.929$ & 0.654 & & & \\
\hline & High & 2.008 & $0.588-6.853$ & 0.266 & & & \\
\hline
\end{tabular}

premenopausal women are less likely to have cardiovascular disorders compared to their men counterpart [46] . Majority of our participants were within the age range of 20-49 years which further buttress the fact that abundance oestrogen hormone present in women prior to menopause protect women from aldosterone-induced hypertension [46]. Furthermore, male sex and hypertension were among predictors of coronary heart diseases [18]. The findings on the predictors of health status are critical as all the sociodemographic variables contributed to the development of one or more of the risk factors for cardiometabolic disorders. WHR is suggested to be the best predictor of CVD risk [12], and it is associated with increased risk to diabetes, hypertension among all ethnic groups [43]. In men, high WHR increased the risk of CVD incidence, morbidity and mortality compared to BMI, and BMI was associated with increased risk of CVDs in women $[12,43]$.

The findings from this study are therefore crucially important in guiding intervention programmes for the university staff and workers generally. Surveillance is crucial in the control and prevention of NCDs [5, 9, 47], especially since some of the variables that influence some of the risk factors like age and gender [27, 28] cannot be controlled. Likewise, there are factors such as socioeconomic status which could in theory be controlled except that the means are not available (e.g. low income, as reported by roughly half our study participants). Literature revealed colossal amounts spent in the management of NCDs [1, 2, 47, 48], making it all the more essential to develop an intervention for control and prevention of NCDs that is not capital intensive and that will include all of the university staff population.

One of the limitations of this study was that the testing for RBS was not good enough to predict prevalence of impaired glucose tolerance or diabetes among the study population. The difficulty was that participants were often too busy to attend following a two-hour post-feeding interval for the RBS testing so that the post-feeding interval was in most cases much longer. Hence it would be advisable to perform fasting blood sugar examination to evaluate the prevalence of diabetes among the study population.

\section{Conclusion}

In conclusion the health status of the study population is borderline. The prevalence rates of high blood pressure and random blood sugar; overweight, obesity and risk WHR are on the increase compared to previous studies, with lifestyle behaviour of university staff [24] a possible explanation for this finding. The findings of this study are useful in the planning of intervention programmes for the 
control of diabetes and hypertension that usually co-exist and share common risk factors like overweight and obesity. With the findings of this study, interventions that can increase physical activities and healthy nutritional lifestyle behaviour should be developed for workers so as to achieve and maintain healthy weight. Health responsibility is key in the control and prevention of NCD, therefore, workers should be empowered with adequate information that can assist them take control of their health. Finally, nurses most especially community/public health nurse practitioners working with institutions should develop interventions that includes awareness campaigns, continuous screening and surveillance to prevent NCDs and their associated disabilities.

\section{Additional file}

Additional file 1: Health status questionnaire (DOCX $14 \mathrm{~kb}$ )

\section{Abbreviations}

BMI: Body mass index; NCDs: Non-communicable diseases; RBS: Random blood sugar; WHR: Waist-hip ratio

\section{Acknowledgements}

The authors wish to express their heartfelt appreciation to the National Open University of Nigeria and to the University of KwaZulu-Natal College of Health Science for their supports in this study. Our deepest appreciation also goes to our participants for their participation in the study.

\section{Availability of data and materials}

All data generated or analysed during this study are are available from the corresponding author on reasonable request.

\section{Author contributions}

Study design: EMJ and BPN: Data collection, analysis and original draft preparation: EMJ; Funding acquisition: EMJ and BPN and Supervision, review and editing: BPN. EMJ and BPN approved the final draft.

\section{Competing interest}

The authors declare that they have no competing interests.

\section{Ethics approval and consent to participate}

Ethical approval was obtained from the National Open University of Nigeria (NOUN) Health Research Ethics Review Committee (NHREC 04) and Biomedical Research Ethics Committee (BREC) and the University of KwaZulu-Natal, Durban, South Africa (BFC423/16). Written and verbal consent was also obtained from each respondent prior to data collection.

\section{Consent for publication}

Not applicable.

\section{Publisher's Note}

Springer Nature remains neutral with regard to jurisdictional claims in published maps and institutional affiliations.

Received: 16 May 2018 Accepted: 10 September 2018

Published online: 20 September 2018

\section{References}

1. van Vliet M, Heymans MW, von Rosenstiel IA, Brandjes DP, Beijnen JH, Diamant M: Cardiometabolic risk variables in overweight and obese children: a worldwide comparison. Cardiovasc Diabetol 2011, 10(1):106.
2. Ali MK, Jaacks LM, Kowalski AJ, Siegel KR, Ezzati M. Noncommunicable diseases: three decades of global data show a mixture of increases and decreases in mortality rates. Health Aff. 2015;34(9):1444-55.

3. Ekwunife Ol, Aguwa CN. A meta analysis of prevalence rate of hypertension in Nigerian populations. J Public Health Epidemiology. 2011;3(13):604-7.

4. Allender S, Wickramasinghe K, Goldacre M, Matthews D, Katulanda P. Quantifying urbanization as a risk factor for noncommunicable disease. Journal of Urban Health. 2011:88(5):906.

5. Noncommunicable diseases [http://www.who.int/mediacentre/factsheets/ fs355/en/].

6. Joseph-Shehu E, Irinoye O, Ajani G. Relationship between blood pressure, body mass index and health promoting lifestyle practices of women in selected rural communities in Osun state Nigeria. Research Journal of Health Sciences. 2016;4(2):112-23.

7. Mukadas AO, Misbau U. Incidence and patterns of cardiovascular disease in north western Nigeria. Nigerian Medical Journal. 2009;50(3):55.

8. Thankappan K, Shah B, Mathur P, Sarma P, Srinivas G, Mini G, Daivadanam M, Soman B, Vasan RS. Risk factor profile for chronic non-communicable diseases: results of a community-based study in Kerala, India. Indian Journal of Medical Research. 2010;131(1):53-63.

9. Deepa M, Pradeepa R, Anjana R, Mohan V. Noncommunicable diseases risk factor surveillance: experience and challenge from India. Indian journal of community medicine: official publication of Indian Association of Preventive \& Social Medicine. 2011;36(Suppl1):S50.

10. Maher D, Waswa L, Baisley K, Karabarinde A, Unwin N, Grosskurth H. Distribution of hyperglycaemia and related cardiovascular disease risk factors in low-income countries: a cross-sectional population-based survey in rural Uganda. Int J Epidemiol. 2010;40(1):160-71.

11. Mehan MB, Surabhi S, Solanki GT. Risk factor profile of non-communicable diseases among middle-income (18-65 years) free-living urban population of India. Int J Diab Dev Ctries. 2006;26(4):169.

12. World Health Organisation: Waist Circumference and Waist-Hip Ratio: Report of a WHO Expert Consultation Geneva, 8-11 December 2008. In.; 2011.

13. Ferreira JRD, Aleluia MM, Figueiredo CVB, LCdL V, Santiago RP, da Guarda CC, Barbosa CG, Oliveira RR, Adorno EV, MdS G. Evaluation of cardiometabolic Parameters among Obese Women Using Oral contraceptives Frontiers in endocrinology. 2017:8:256.

14. World Health Organization: Global health risks: mortality and burden of disease attributable to selected major risks: World Health Organization; 2009.

15. Huxley R, Mendis S, Zheleznyakov E, Reddy S, Chan J. Body mass index, waist circumference and waist: hip ratio as predictors of cardiovascular risk-a review of the literature. Eur J Clin Nutr. 2010;64(1):16-22.

16. Schmidt M, Bøtker HE, Pedersen L, Sørensen HT. Young adulthood obesity and risk of acute coronary syndromes, stable angina pectoris, and congestive heart failure: a 36-year cohort study. Annals of epidemiology. 2014;24(5):356-61 e351.

17. Bastien M, Poirier P, Lemieux I, Després J-P. Overview of epidemiology and contribution of obesity to cardiovascular disease. Prog Cardiovasc Dis. 2014; 56(4):369-81.

18. Barbero U, D'Ascenzo F, Nijhoff F, Moretti C, Biondi-Zoccai G, Mennuni M, Capodanno D, Lococo M, Lipinski MJ, Gaita F. Assessing risk in patients with stable coronary disease: when should we intensify care and follow-up? Results from a meta-analysis of observational studies of the COURAGE and FAME era Scientifica. 2016;2016

19. Isara AR, Okundia PO. The burden of hypertension and diabetes mellitus in rural communities in southern Nigeria. The Pan African medical journal. 2015;20.

20. Msyamboza KP, Mvula CJ, Kathyola D. Prevalence and correlates of diabetes mellitus in Malawi: population-based national NCD STEPS survey. BMC Endocr Disord. 2014;14(1):41.

21. Ayah R, Joshi MD, Wanjiru R, Njau EK, Otieno CF, Njeru EK, Mutai KK. A population-based survey of prevalence of diabetes and correlates in an urban slum community in Nairobi, Kenya. BMC Public Health. 2013;13(1):371.

22. Hall V, Thomsen RW, Henriksen O, Lohse N. Diabetes in sub Saharan Africa 1999-2011: epidemiology and public health implications. A systematic review. BMC Public Health. 2011;11(1):564.

23. Msyamboza KP, Kathyola D, Dzowela T. Anthropometric measurements and prevalence of underweight, overweight and obesity in adult Malawians: nationwide population based NCD STEPS survey. Pan African Medical Journal. 2013:15(1)

24. Shehu R, Onasanya S, Onigbinde T, Ogunsakin E, Baba D. Lifestyle, fitness and health promotion initiative of the University of Ilorin, Nigeria: an 
educational media intervention. Ethiopian Journal of Environmental Studies and Management. 2013;6(3):273-9.

25. Bacopoulou F, Efthymiou V, Landis G, Rentoumis A, Chrousos GP. Waist circumference, waist-to-hip ratio and waist-to-height ratio reference percentiles for abdominal obesity among Greek adolescents. BMC Pediatr. 2015;15(1):50.

26. Ogah OS, Madukwe OO, Chukwuonye II, Onyeonoro UU, Ukegbu AU, Akhimien MO, Onwubere BJ, Okpechi IG. Prevalence and determinants of hypertension in Abia state Nigeria: results from the Abia state noncommunicable diseases and cardiovascular risk factors survey. Ethnicity \& disease. 2016;23(2):161-7.

27. Bell K, Twiggs J, Olin BR. Hypertension: the silent killer: updated JNC-8 guideline recommendations. Alabama Pharmacy Association. 2015:1-8,

28. Ulasi II, ljoma CK, Onwubere BJ, Arodiwe E, Onodugo O, Okafor C. High prevalence and low awareness of hypertension in a market population in Enugu, Nigeria. International journal of hypertension, 2011;2011.

29. Nair M, Ali MK, Ajay VS, Shivashankar R, Mohan V, Pradeepa R, Deepa M, Khan HM, Kadir MM, Fatmi ZA. CARRS surveillance study: design and methods to assess burdens from multiple perspectives. BMC Public Health. 2012;12(1):701

30. Mokdad AH. Global non-communicable disease prevention: building on success by addressing an emerging health need in developing countries. $J$ Health Specialties. 2016;4(2):92.

31. Akintunde A, Salawu A, Opadijo O. Prevalence of traditional cardiovascular risk factors among staff of Ladoke Akintola University of technology, Ogbomoso, Nigeria. Niger J Clin Pract. 2014;17(6):750-5.

32. Imuala SO, Ayankogbe OO, Olatona FA, Olamoyegun MA, Igwe UO, Sabir AA, Fasanmade O. Obesity among health service providers in Nigeria: danger to long term health worker retention? Pan Afr Med J. 2015;22(1). https://doi.org/10.11604/pami.2015.22.1.5586

33. Faul F, Erdfelder E, Lang A-G, Buchner A. G* power 3: a flexible statistical power analysis program for the social, behavioral, and biomedical sciences. Behav Res Methods. 2007;39(2):175-91.

34. Chobanian AV, Bakris GL, Black HR, Cushman WC, Green LA, Izzo JL Jr, Jones DW, Materson BJ, Oparil S, Wright JT Jr, et al. The seventh report of the joint National Committee on prevention, detection, evaluation, and treatment of high blood pressure: the JNC 7 report. Jama. 2003;289(19):2560-72.

35. About Adult BMI [https://www.cdc.gov/healthyweight/assessing/bmi/adult $\mathrm{bmi} / \mathrm{l}$.

36. Suleiman IA, Amogu EO, Ganiyu KA. Prevalencia y control de la hipertensión en una comunidad semi-urbana del delta del Níger, Nigeria. Pharmacy Practice (Granada). 2013;11(1):24-9.

37. Adedoyin RA, Mbada CE, Balogun MO, Martins T, Adebayo RA, Akintomide A, Akinwusi PO. Prevalence and pattern of hypertension in a semiurban community in Nigeria. Eur J Cardiovasc Prev Rehabil. 2008;15(6):683-7.

38. Chukwuonye II, Chuku A, John C, Ohagwu KA, Imoh ME, Isa SE, Ogah OS, Oviasu E. Prevalence of overweight and obesity in adult Nigerians-a systematic review. Diabetes, Metabolic Syndrome and Obesity: Targets and Therapy. 2013;6:43

39. Kortt MA, Dollery B. Religion and BMI in Australia. J Relig Health. 2014;53(1): $217-28$

40. Lycett D. The association of religious affiliation and body mass index (BMI): an analysis from the health survey for England. J Relig Health. 2015;54(6): 2249-67.

41. Levitt NS. Diabetes in Africa: epidemiology, management and healthcare challenges. Heart. 2008;94(11):1376-82.

42. Dahiru T, Jibo A, Hassan A, Mande A. Prevalence of diabetes in a semiurban community in northern Nigeria. Niger J Med. 2008;17(4):414-6.

43. Lear S, James P, Ko G, Kumanyika S. Appropriateness of waist circumference and waist-to-hip ratio cutoffs for different ethnic groups. Eur J Clin Nutr. 2010;64(1):42-61.

44. New guidelines broaden definition of hypertension [https://www.healio. com/cardiology/vascular-medicine/news/online/\%7B1 1 efb029-2475-4a299bb3-4d882fc37272\%7D/new-guidelines-broaden-definition-ofhypertension].

45. Whelton PK. Muntner P, Carey RM, Gidding S, Jones DW, Taler SJ, Wright JT, Potential US population impact of the 2017 American College of Cardiology/American Heart Association high blood pressure guideline. J Am Coll Cardiol. 2017:24414.

46. Maranon R, Reckelhoff JF. Sex and gender differences in control of blood pressure. Clin Sci. 2013;125(7):311-8.
47. Alwan A, MacLean DR, Riley LM, d'Espaignet ET, Mathers CD, Stevens GA, Bettcher D. Monitoring and surveillance of chronic non-communicable diseases: progress and capacity in high-burden countries. Lancet. 2010; 376(9755):1861-8.

48. Wagner $\mathrm{K}$, Brath $\mathrm{H}$. A global view on the development of noncommunicable diseases. Prev Med. 2012;54(54):S38-41.

\section{Ready to submit your research? Choose BMC and benefit from:}

- fast, convenient online submission

- thorough peer review by experienced researchers in your field

- rapid publication on acceptance

- support for research data, including large and complex data types

- gold Open Access which fosters wider collaboration and increased citations

- maximum visibility for your research: over $100 \mathrm{M}$ website views per year

At $\mathrm{BMC}$, research is always in progress.

Learn more biomedcentral.com/submissions 